\title{
Treatment of Biomass Gasification Wastewaters Using Reverse Osmosis
}

S. E. Petty

S. D. Eliason

M. M. Laegreid

September 1981

Prepared for the U.S. Department of Energy under Contract DE-AC06-76RL.O 1830

Pacific Northwest Laboratory

Operated for the U.S. Department of Energy by Battelle Memorial Institute 
NOTICE

This report was prepared as an account of work sponsored by the United States Government. Neither the United States not the Department of Energy, nor any of their employees, nor any of their contractors, subcontractors, or their employees, makes any warranty, express or implied, or assumes any legal liability or responsibility for the accuracy. completeness or usefulness of any intormation, apparatus, product or process disclosed, or represents that its use would not infringe privately owned rights.

The views, opinions and conclusions contained in this report are those of the contractor and do not necessarily represent those of the United States Government or the United States Department of Energy.

\author{
PACIFIC NORTHWEST LABORATORY \\ operated by \\ BATTELLE \\ for the \\ UNITED STATES DEPARTMENT OF ENERGY \\ Under Contract DE-AC06-76RLO 1830
}
Printed in the United States of America Available from
National Technical tnformation Service United States Depariment of Cornmerce 5285 Port Royal Road
Springfield, Virginia 22151

Price: Prinsed Copys $\therefore$ Microtiche $\$ 3.00$

Nris

- Pages Selling Price

$001-025$

026-050

$\$ 400$

$051-075 \quad \$ 5.25$

$076-100 \quad 56.00$

$101-125 \quad \$ 6.50$

126. $150 \quad \$ 7.25$

$151-175 \quad 58.00$

$176-200 \quad 59.00$

$201-225 \quad \$ 9.25$

$226-250 \quad 59.50$

$251-275 \quad 51075$

$276-300 \quad 511.00$ 


\section{S.E. Petty}

S.D. ETiason

M.M. Laegreid

September 1981

Prepared for the

U.S. Department of Energy

Under Contract No. DE-ACO6-76RL0-1830

Pacific Northwest Laboratory

Richland, Washington 99352 


\section{DISCLAIMER}

Use of brand or trade names in this report does not constitute endorsement of equipment by the U.S. Department of Energy or Pacific Northwest Laboratory. 


\section{ACKNOWLEDGMENTS}

The authors gratefully acknowledge the financial support of Mr. Ray Coste110, U.S. Department of Energy, and N. C. Painter who typed the manuscript. 


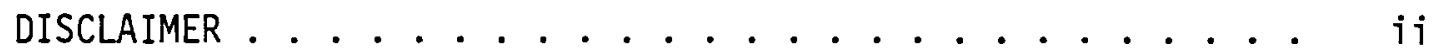

ACKNOWLEDGMENTS. ....................... $i$. .

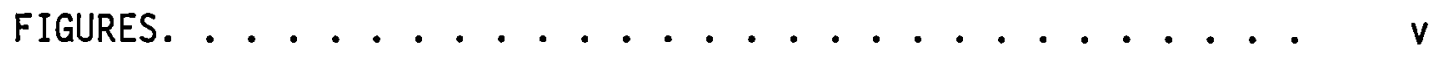

TABLES ............................... vi

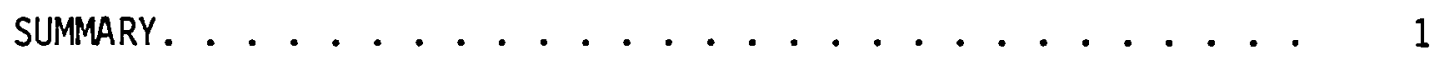

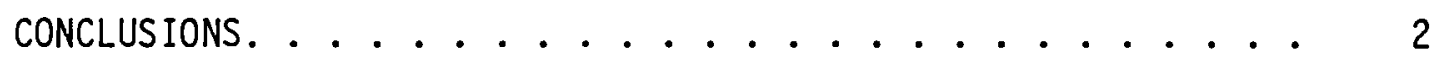

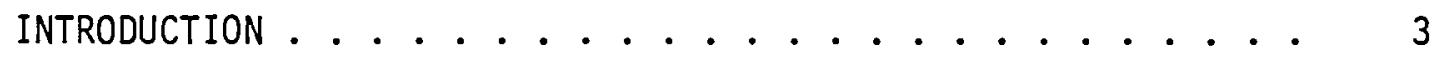

LITERATURE REVIEW. ....................... 4

THEORY . . . . . . . . . . . . . . 6

EXPERIMENTAL SETUP AND PROCEDURE . . . . . . . . . . 9

EXPERIMENTAL SETUP................ 9

EXPERIMENTAL PROCEDURE. . . . . . . . . . . . . . . . . . . 9

ANALYTICAL MEASUREMENTS . . . . . . . . . . . . . . 13

EXPERIMENTAL FEEDS. . . . . . . . . . . . . 13

RESULTS. ........................... 18

SALT REJECTION. . . . . . . . . . . . . 18

PERMEATE FLUXES .................... 18

CHEMICAL OXYGEN DEMAND REMOVAL. ........... 18

CHEMICAL OXYGEN DEMAND VS TIME. .......... 20

COLOR REMOVAL .................... 20

DISCUSSION OF RESULTS. . . . . . . . . . . . . . 24

SALT REJECTION. . . . . . . . . . . . . . . 24

PERMEATE FLUXES ................... . . . 24

CHEMICAL OXYGEN DEMAND. ................ 27

COLOR REMOVAL .................. 27

REFERENCES . . . . . . . . . . . . . . . . 28

APPENDIX A: REVERSE OSMOSIS TEST PROCEDURE. . . . . . . 30

APPENDIX B: COMPUTATION OF ACTIVITY COEFFICIENTS. . . . . . 34 


\section{LIST OF FIGURES}

No. $\quad$ Page

1 Reverse Osmosis Flow Schematic .......... 10

2 Reverse Osmosis Pressure Vessel. . . . . . . . . 11

3 Initial Chemical Oxygen Demand for BGW Feeds . . . . . 15

4 Solids Levels for Initial Feed Samples . . . . . . 16

5 Chemical Oxygen Demand Removal vs Time........ 21

6 Permeate Chemical Oxygen Demand vs Time. . . . . . 22 


\section{LIST OF TABLES}

No. $\quad$ Page

I Feeds Used During RO Experiments . . . . . . . . . 13

2 Chemical Analys is of BGW Feeds . . . . . . . . . 17

3 Average Salt Rejection for Seven Test Feeds. . . . . . 19

4 Average Permeate Fluxes for Seven BGW Feeds. . . . . . . 19

5 Average Chemical Oxygen Demand Removal for Seven BGW Feeds................. 20

6 Average Color Removal for Seven BGW Feeds. . . . . . . 23

7 Solvent and Solute Transport Parameters. . . . . . . 25 


\section{SUMMARY}

Reverse osmosis (RO) was evaluated as a treatment technology for the removal of organics from biomass gasification wastewaters (BGW) generated from an experimental biomass gasifier at Texas Tech University. Wastewaters were characteristically high in chemical oxygen demand (COD) with initial values ranging from 32,000 to $68,000 \mathrm{mg} / 1$. Since $R O$ is normally considered a complementary treatment technology, wastewaters were pretreated by biological or wet air oxidation (WAO) processes. One set of experiments were run using untreated wastewaters to compare membrane performance with those experiments using pretreated wastewaters. Experiments were run for 8-10 hrs using UOP's TFC- 85 membrane operating at $700 \mathrm{psig}$ and $18-20^{\circ} \mathrm{C}$. This membrane is similar to the NS-100, a membrane known for being effective in the separation of organics from solution.

Separation of organics from solution was determined by COD removal. Removal percentages for biologically pretreated wastewaters averaged $98 \%$ except for one group of runs averaging $69 \%$ removal. This exception was probably due to the presence of milk solids in the feed. Use of RO on WAO pretreated wastewaters and unpretreated feeds resulted in $90 \% \mathrm{COD}$ removal.

Membrane degradation was observed when using full-strength and WAO pretreated feeds, but not when using feeds that had undergone biological pretreatment. Data indicate that membrane degradation may be due to the presence of acetic and propionic acids. These acids, present in large quantities in BGW, are removed in biological pretreatment technologies but not in the other pretreatment options, a fact which correlates we 11 with superior permeate quality using feeds having had biological pretreatment. Longer, $26 \mathrm{hr}$, experiments were completed to verify this correlation and no degradation of the membrane surface, using biologically pretreated feed, was observed.

Color removal was computed for the majority of experiments completed. Overa11, $99-100 \%$ of the total color was removed from BGW feeds, values which coincide with those reported in the literature for other wastewaters. 


\section{CONCLUSIONS}

1) Reverse osmosis is an effective treatment technology for the removal of organics from $B G W$, provided the wastewater has undergone biological pretreatment.

2) Reverse osmosis does not appear to be as effective if preceeded by WAO pretreatment.

3) The presence of acetic and propionic acids in BGW restricts use of RO to situations in which these compounds are removed during pretreatment processes (e.g., biological pretreatment).

4) Color can be completely removed from BGW by RO.

5) In $26 \mathrm{hr}$ experiments on biologically pretreated BGW, no decrease in product quality or flow rate was observed, indicating negligible membrane degradation. 


\section{INTRODUCTION}

Reverse osmosis is one of many processes which can be used to treat industrial wastewaters, and was one of four technologies investigated for the treatment of BGW. These wastewaters are by-products generated during the pyroiysis of agricultural residue and manures for energy production. In order for the pyrolysis process to be a more environmentally acceptable method of energy production, the wastes or wastewaters must be treated in an environmentally acceptable manner. The programmatic goal of this research was to determine acceptable treatment options for the cleanup of BGW.

Other treatment processes investigated included innovative biological treatment, solvent extraction (Maxham and Be11, 1980), and WAO.

This paper presents results of experimental studies conducted to evaluate the feasibility of using RO to treat BGW. Additional papers will present results of solvent extraction and WAO experiments.

As a treatment alternative, Ro must be considered a complimentary technology to biological, WAO, or possibly solvent extraction processes. In general $R O$ is an excellent purification treatment technology but becomes progressively poorer (as a treatment technology) as the solute concentration increases. Since BGW has very high COD loadings $(35,000-$ $68,000 \mathrm{mg} / 1)$, initial pretreatment with other technologies was considered necessary. In these experiments both biological and WAO pretreatment processes were used. Pretreatment processes also provided the additional benefit of removing suspended solids, which are normally detrimental to the operation of $\mathrm{RO}$ processes. 


\section{LITERATURE REVIEW}

General references addressing RO are available at a variety of technical leve1s. Lacy (1972) provides a basic description of RO processes and theory. Perry and Chilton (1973) and Weber (1972) present an intermediate level discussion of existing Ro theories and existing literature. The following section dealing with theory uses their descriptions. A more extensive theoretical review of RO (mainly with respect to desalination) is available through Merten (1966).

The early motivation for using RO was for generation of potable water from saltwater, i.e., desalination. Associated with this need, from both a water quality and flux standpoint, was the early success in development of thin-filmed cellulose acetate (CA) membranes. Cellulose acetate membranes are very effective at desalination and continue to be used for that purpose. For this reason, most of the early theory and literature are related to this process (desalination) and membrane (CA).

Considerable work has been completed on characterization of CA membranes since then, especially by Matsuura and Sourirojan (1971, 1973, 1976a, 1977a, 1977b, and 1978). Their work has emphasized prediction of RO separations using $\Delta v_{s}$, a parameter which indicates relative hydrogen bonding ability. However, most of the correlations suggested by Matsuura and Sourirajan are limited to dilute solute solutions (0.001-0.003 gmoles/1).

After the first successes with desalination using CA membranes, investigators began evaluating the removal of organics using $R O$ and $C A$ membranes. However, CA membranes were found to be relatively less effective (compared with desalination) in removal of organics. Beginning in the early 1970's considerable effort was put into developing an effective membrane for the removal of organics. Fang and Chian (1976) summarized some of their experimental studies on 12 such membranes using 13 polar, low molecular weight, organics. They reported that crosslinked polyethylenimine and aromatic polyamide membranes were much more effective than CA membranes in removing organics.

Fang and Chian (1975 and 1976) also investigated polyethylenimine membranes, including the NS-100, suggesting optimal conditions for membrane formation, and the effectiveness in terms of solute separation 
of alcohols, amines, and aliphatic acids. They found that the $\Delta \nu_{s}$ parameter, used for prediction of solute separation in CA membranes, could not be used to predict separation in the NS-100 membrane. Their studies did show the trend that separation of aliphatic acids increased as the degree of acid dissociation increased. In particular, solute separations of $90 \%$ were reported using $0.001-0.01 \mathrm{M}$ solutions of totally dissociated acetic acid (a major constituent in our wastewaters). These same membranes have also been used for the removal of salt (Riley et al., 1976, 1977, 1980; Reed and Wilson, 1977). Additional work was recently performed by Petty and Maxham (1980) using cross-linked polyethylenimine (TFC 17-85, also known as the NS-100) membrane for separation of ethanol/water mixtures. Rejection rates were similar to those reported by Fang and Chian (1976). 


\section{THEORY}

Reverse osmosis is a membrane separation process typicaliy used for the removal of solutes at low concentration from aqueous solutions. Simple osmotic processes are defined by the movement of solute from a concentrated solution into an adjacent, more dilute solution. The driving force for this movement toward an equilibrium concentration is defined as the osmotic pressure $(\pi)$. In RO, the osmotic process is reversed by application of an external pressure to the concentrated solution, which is separated from the dilute solution by a semi-permeable membrane. This external pressure overcomes the osmotic pressure and forces solvent (water) through the membrane. The membrane itself enhances separation through chemical and/or steric effects, although these effects are not well understood. Temperature and $\mathrm{pH}$ will also strongly affect the performance of RO processes (Weber, 1972) mainly by changing the effectiveness of the membrane itself.

The theory of RO can be examined from several levels of derivation. Only the equations used for characterizing a particular membrane will be presented here (Weber, 1972). The reader is referred to Merten (1966) for a description of osmotic pressure in terms of chemical potential and activity coefficients.

Two equations are commonly used when characterizing separation using RO. The first (Equation 1) describes solvent (water) flux through a particular membrane, and the second (Equation 2) describes solute flux through a membrane.

$$
\begin{aligned}
& F_{w}^{0}=W_{p}\left(\Delta P-\Delta \pi^{0}\right) \\
& F_{i}^{0}=K_{p}\left(\Delta C_{i}\right)
\end{aligned}
$$

where

$$
\begin{aligned}
F_{W}^{0} & =\text { solvent flux }\left(\mathrm{g} / \mathrm{cm}^{2}-\mathrm{sec}\right) \\
F_{i}^{0} & =\text { solute flux }\left(\mathrm{g}-\mathrm{coD} / \mathrm{cm}^{2}-\mathrm{sec}\right) \\
\Delta P & =\text { applied pressure drop across membrane }(\mathrm{atm}) \\
\Delta \pi^{\circ} & =\text { osmotic pressure drop across membrane }(\mathrm{atm}) \\
\Delta C_{i} & =\text { change in solute concentration across membrane }\left(\mathrm{g}-\mathrm{coD} / \mathrm{cm}^{3}\right) \\
W_{p} & =\text { water permeability constant }\left(\mathrm{g} / \mathrm{cm}^{2}-\mathrm{sec}-\mathrm{atm}\right) \\
K_{p} & =\text { solute coefficient of permeability }(\mathrm{cm} / \mathrm{sec})
\end{aligned}
$$


The two coefficients, $W_{p}$, and $K_{p}$, are normally specific to the type of membrane being used and the method of manufacture. The water permeability constant is a function of the ability of water to diffuse through a membrane; the water concentration; membrane thickness; and thermodynamic parameters such as molar volume, temperature, and the gas constant. Solute permeability, as defined by $K_{p}$, is a function of the ability of the solute to pass through the membrane and the membrane thickness.

From Equations 1 and 2, several trends describing product quantity and quality can be predicted and are observed in actual practice.

Frist, an increase in applied pressure $(\Delta P)$ will increase water quality if the feed solute concentration remains constant. This follows since an increase in applied pressure increases solvent fluxes (Equation 1), but solute fluxes (Equation 2) remain essentially constant. Thus, the concentration of solute in the permeate is reduced, improving water quality.

Second, an increase in solute concentration, holding applied pressure constant, will reduce water quality and quantity. Two factors are responsible for this trend. First, Equation 2 shows that an increase in solute concentration results in a larger solute flux, decreasing water quality. The problem is compounded by the fact that increasing the solute concentration increases the osmotic pressure $(\Delta \pi)$. This, in turn, reduces $\left(\Delta \mathrm{P}-\Delta \pi^{\circ}\right)$ in Equation 1 causing a decrease in permeate flux and adding to the deterioration in water quality.

Third, if one has a closed feed system, the permeate flux will decrease with time. This follows by noting that the solute is being concentrated in the feed as permeate is removed. Increasing feed concentration decreases the flux as described above.

Lastly, a decrease in water quality is observed with decreasing applied pressure since permeate flux (Equation 1) decreases and solute flux (Equation 2) remains constant.

Another parameter often used in describing membrane performance is $\mathrm{R}^{\circ}$, the solute rejection percentage (Equation 3 ).

$$
R^{\circ}=\left(\frac{C_{c}-C_{p}}{C_{c}}\right) \cdot 100
$$


where

$$
\begin{aligned}
& C_{c}=\text { concentration of solute in the reject stream }(\mathrm{mg} / 1) \\
& C_{p}=\text { concentration of solute in the permeate stream }(\mathrm{mg} / 1)
\end{aligned}
$$

However, since wastewater treatment processes are conventionally described by the removal of an impurity based on initial feed concentrations, a different parameter, $R$, as described in Equation 4, will be used instead of $R^{\circ}$. Equation 4 will be used to describe removal of $C O D$, solids, and color. Note that in general, for the same experimental run, $R^{\circ}$ will be greater than $R$ since $C_{C}$ is greater than $C_{i}$.

$$
R=\left(\frac{C_{i}-C_{p}}{C_{i}}\right) \cdot 100
$$

where

$$
\begin{aligned}
& C_{i}=\text { concentration of solute in the feed stream } \\
& C_{p}=\text { concentration of solute in the permeate stream }
\end{aligned}
$$


.

. 


\section{EXPERIMENTAL SETUP AND PROCEDURE}

\section{EXPERIMENTAL SETUP}

Reverse osmosis experiments were completed using a modified Soltech RO unit. Modifications to the unit were required because its flow capacity was too large for the limited volume of BGW available for experimental work. Only the pump, motor, and portions of the tubing were used from the original unit. Figure 1 presents a simplified schematic of the RO experimental setup. Changes to the unit included a special pressure vessel, added pressure gages, and modified plumbing. Additional pressure gages were placed on the front and back ends of the system to determine pressure drops across the membrane. In addition, because the original unit was designed to handle flows 1000 times those necessary for this study, a by-pass flow loop was added, reducing flow. However, this reduction of flow was accompanied by a heat generation and dissipation problem that was solved with the addition of a heat exchanger. An automatic sampling device was also added to the setup to collect permeate samples at set intervals making it possible to run tests over long periods of time with minimal supervision.

The pressure vessel was custom built for these experiments and was machined from 316 stainless steel. Figure 2 illustrates flow patterns through the pressure vessel. The pressure vessel consists of two halves connected by four nut and bolt combinations and sealed by an "0" ring. Feed passes across the face of the membrane, passing small amounts of permeate through the membrane. Remaining fluid exits as the reject stream. The porous plate serves as support to the membrane itself. EXPERIMENTAL PROCEDURE

The following text summarizes the RO experimental procedure. A detailed procedure is given in Appendix $A$.

Initially a membrane was cut from a membrane sheet and secured into the pressure vesse1. The pressure vessel was then inserted into the flow loop and the entire system flushed with distilled water. Once the system was rinsed thoroughly, a sodium chloride solution was added, displacing the distilled water. The unit was operated at a pressure of 650-750 psi with sample permeate fluxes taken every ten min. Permeate 


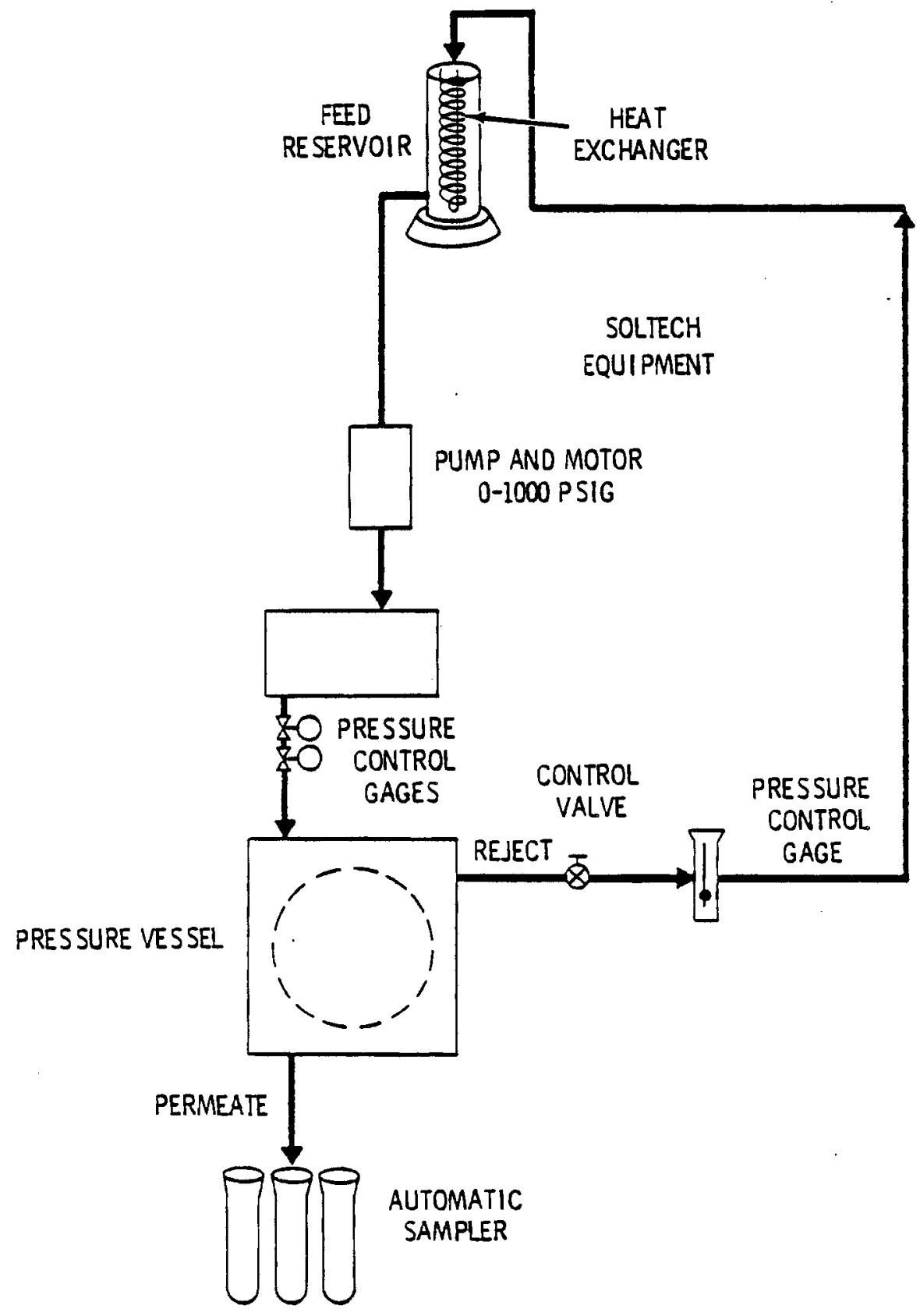

FIGURE 1. Reverse Osmosis Flow Schematic 


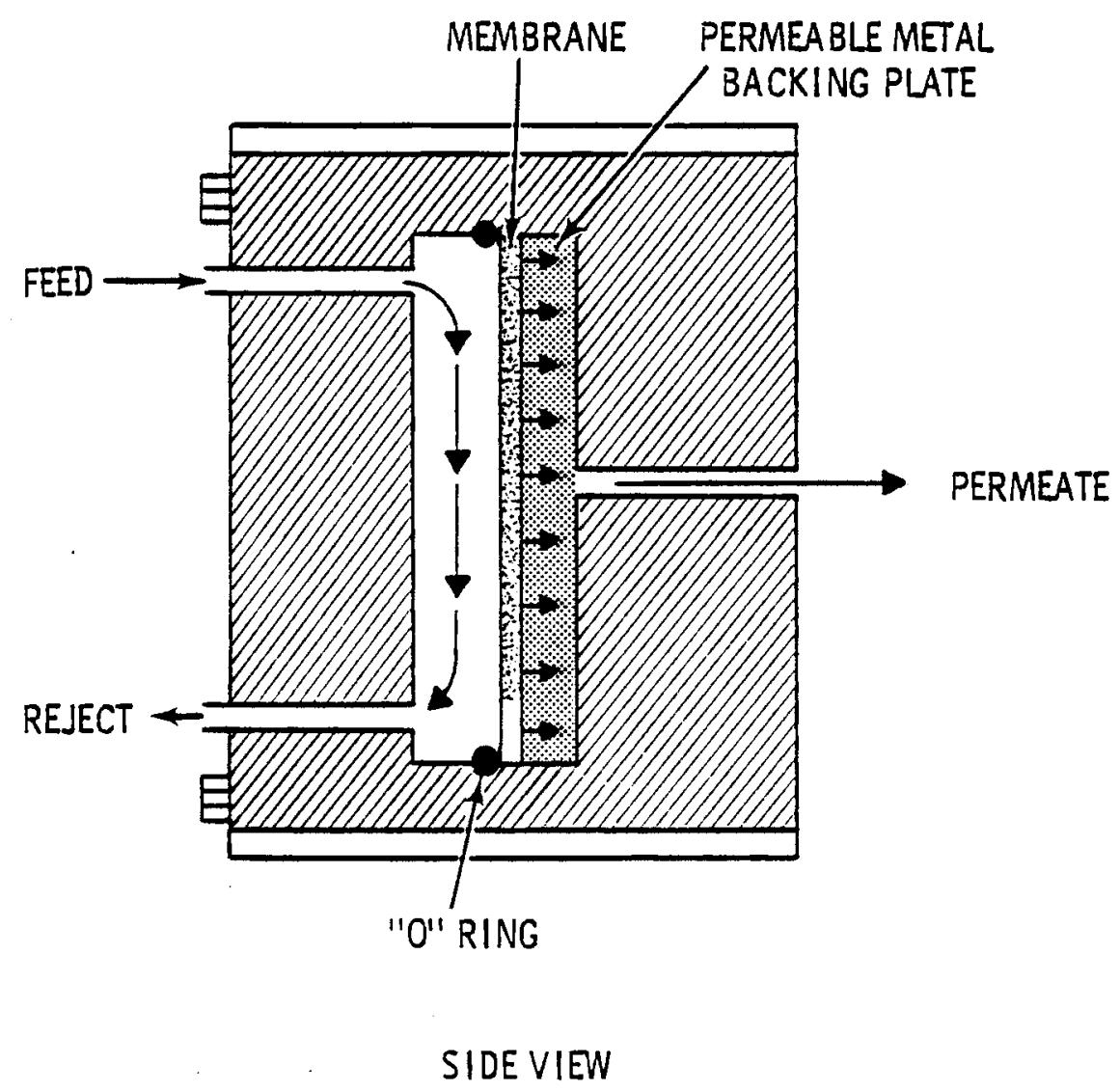

FIGURE 2. Reverse Osmosis Pressure Vessel Flow Patterns 
conductivity was measured after 30 min of operation. If $\mathrm{NaCl}$ rejection was $98 \%$ or better, the membrane was classified "tight" and the testing sequence continued. However, if the membrane had a $\mathrm{NaCl}$ rejection rate below $98 \%$, the membrane was replaced and the entire testing sequence started again. After a membrane was classified "tight," the salt solution was removed from the RO unit and the entire flow loop rinsed with distilled water. Following a thorough rinsing, the unit was fed the actual sample feed. A feed sample was taken as soon as the internal piping void volume distilled water had completely mixed with the actual sample. Almost simultaneously the automatic sampler was activated, collecting samples at 15 min intervals. Pressure and temperature were monitored at half-hr intervals to ensure pressure across the membrane remained constant and that temperature stayed below $35^{\circ} \mathrm{C}$. Permeate samples were taken until the feed supply was depleted.

Once the feed was depleted, the system was again rinsed with distilled water followed by addition of another salt solution to check membrane integrity. The remaining piping void feed volume was saved for further study. Beginning feed, permeate, and final feed volumes were measured and recorded in a laboratory notebook along with salt rejection data and all temperature and pressure values.

As we became more familiar with the operational characteristics of the RO unit, it became apparent. that some modifications to the setup and protocol were necessary. These changes are described in the following paragraphs.

Heat generated by viscous dissipation was originally removed by using a copper tube heat exchanger. Later, feeds containing substantial amounts of ammonia, which caused copper dissolution, necessitated using a glass tube heat exchanger.

Mass Balance, in terms of flow, COD, and color, were continually calculated to monitor experimental techniques and accuracy. The original technique for switching from distilled water to BGW feed was found to be adding excessive distilled water to the feed. A procedure was devised in which the lines were switched simultaneously. This procedure was replaced by adding two three-way valves to the system which resulted in a very accurate (in terms of flow volume) switch from distilled water to BGW feed. This same procedure, in reverse, was used to switch from feed to distilled water on completion of an experimental run. 
ANALYTICAL MEASUREMENTS

Analytical measurements for COD, total solids, dissolved solids, suspended solids, and color were determined for all test runs completed. Both suspended solids and dissolved solids were measured in order to check the accuracy of total solids values. The procedures used for COD and solids determinations were taken from "Standard Methods for the Examination of Water and Wastewater" (Standard Methods, 14th Edition, 1975). The procedure used for color analysis was obtained from the Weyerhaeser Company Research Division, Tacoma, Washington. Their analysis is essentially the same procedure that has been approved by the Environmental Protection Agency, Cincinnati, Ohio (EPA, 1976).

\section{EXPERIMENTAL FEEDS}

A total of 7 sets of experimental feeds were used during this program resulting in the completion of $33 \mathrm{RO}$ experiments. Throughout the following results and discussion section, reference is made to these feeds through abbreviations listed in Table 1.

TABLE 1. Feeds Used During RO Experiments

Feed Abbreviation

Set No.

I

II

III $\quad 10: 1$

IV $\quad \mathrm{AN}-4$

V

VI

VII
$25: 1$

AER $1-3$

BGW 6

WAO
Description of Feed

Third set of BGW (Maxham, 1981) pretreated in anaerobic biological units 1,2 , or 3 at $50: 1$ dilution including the addition of $2 \mathrm{~g} / 1 \mathrm{milk}$ solids.

Fourth set of BGW pretreated in anaerobic biological units 1,2 , or 3 at $25: 1$ dilution.

Fourth set of BGW pretreated in anaerobic biological units 1 or 2 at 10:1 dilution.

Fourth and fifth sets of BGW pretreated with high rate fixed film (HRFF) and anaerobic (fourth reactor) biological processes.

Second, third, fourth, and fifth sets of BGW pretreated in aerobic biological process units 1,2 , or 3 .

Sixth set of BGW without pretreatment.

A set of feeds which have undergond pretreatment by WAO. 
As shown in the table, most of the feeds are effluents from Maxham's biological units (1980 and 1981). Since RO is projected for use as a purification step, treatment of Maxham's biological effluents was a logical next step. All BGW feeds were obtained from the biomass gasifier at Texas Tech University. Biomass gasification wastewater 6 feed did not receive any pretreatment. Wet air oxidation feed waS BGW 6 pretreated by WAO at three levels of severity. Dilution factors under the description category of Table 1 refer to the level which BGW were diluted prior to biological treatment.

Composition data for all feeds except WAO are presented in Figures 3 and 4 and Table 2. Figure 3 presents initial COD values for the first six sets of feeds tested. As one would expect, COD levels for undiluted feeds are much higher than for diluted feeds. Figure 4 illustrates total, dissolved, and suspended solids levels for five of seven feeds. Total solids values for each set of feeds are given in parentheses above each column, suspended solids as the height of the shaded portion of the column, and dissolved solids as the unshaded height of each column. Solids levels for 50:1 feeds were very low (total solids less than 1 $\mathrm{mg} / \mathrm{T}$ ) and therefore not included in Figure 4 . Solids level in WAO feeds were extremely variable (due to variability in pretreatment) and therefore not plotted.

Table 2 provides an extensive characterization of BGW feeds used during these experiments. Besides solids and COD values, total organic carbon (TOC), metals, and nitrogen values are given in the table. One interesting point is the apparent increase in $\mathrm{pH}$ with increasing ammonia concentration. Variability in feed samples is due to changes in operating conditions of the gasifier from which the samples were obtained. 


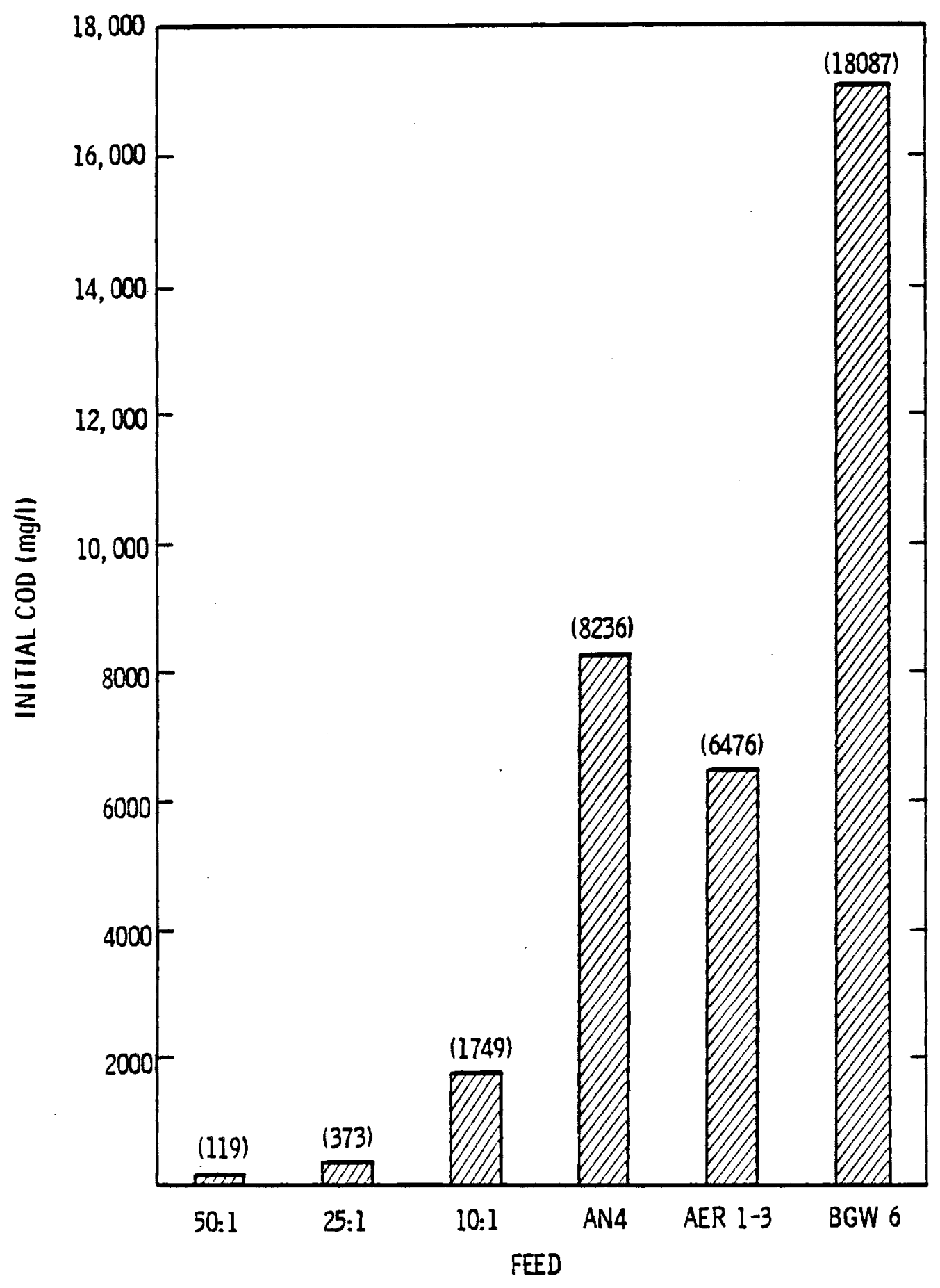

FIGURE 3. Initial Chemical Oxygen Demand for BGW Feeds 


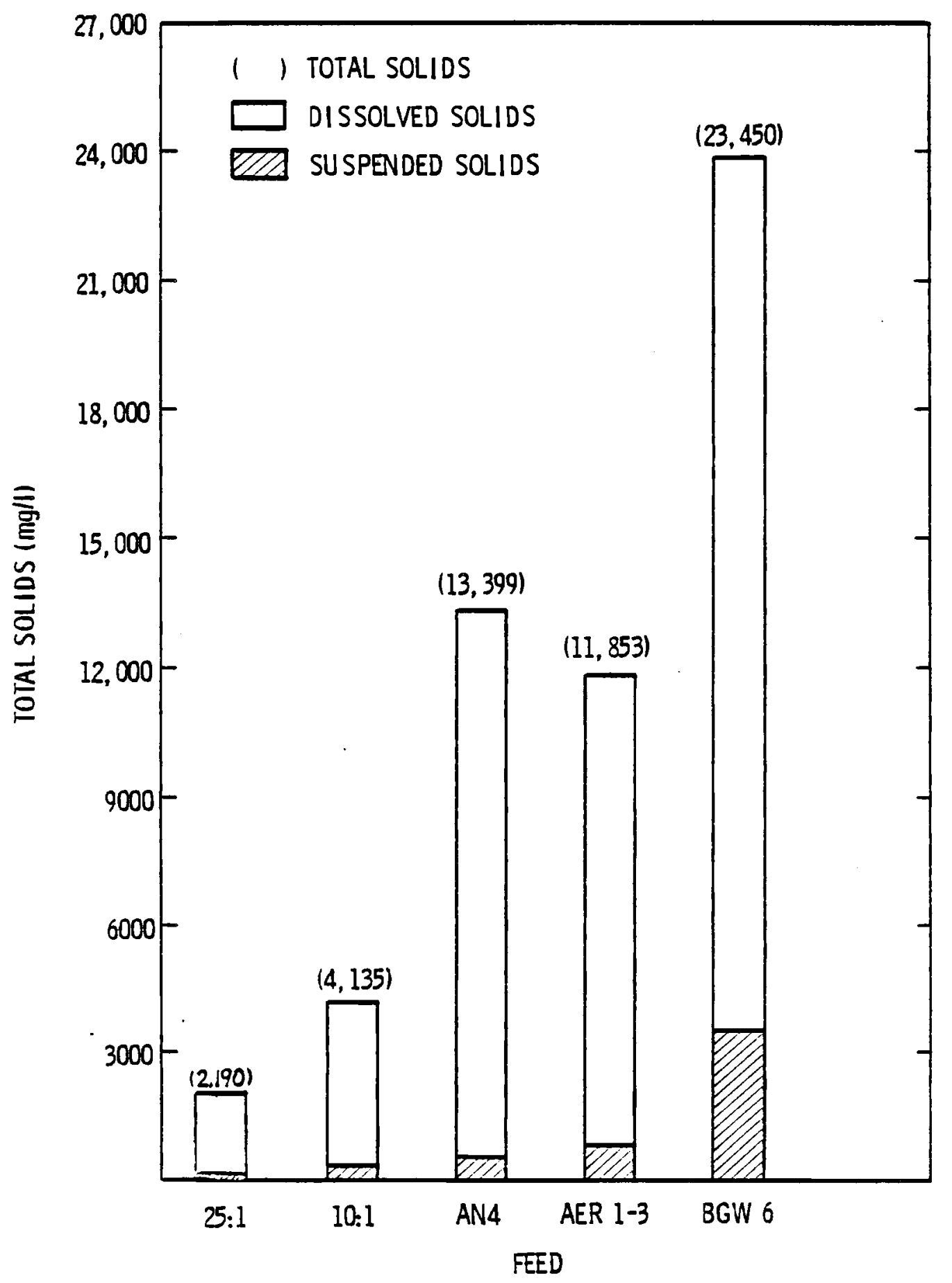

FIGURE 4. Solids Levels for Initial Feed Samples 
TABLE 2. Chemical Analysis of BGW Feeds

(A11 Units mg/1 Unless Noted)

\begin{tabular}{|c|c|c|c|c|c|}
\hline Chemical Analys is & $\begin{array}{l}\text { Test I } \\
\text { Feed }\end{array}$ & $\begin{array}{l}\text { Test II } \\
\text { Feed } \\
\end{array}$ & $\begin{array}{l}\text { Test I I I } \\
\text { Feed } \\
\end{array}$ & $\begin{array}{l}\text { Test IV } \\
\text { Feed } \\
\end{array}$ & $\begin{array}{l}\text { Test V } \\
\text { Feed } \\
\end{array}$ \\
\hline $\begin{array}{l}\text { Total Organic } \\
\text { Carbon (TOC) }\end{array}$ & 334 & 916 & 2,290 & $16,900 *$ & $16,500 *$ \\
\hline $\begin{array}{l}\text { Chemical 0xygen } \\
\text { Demand (COD) }\end{array}$ & 119 & 373 & 1,749 & 8,236 & 6,476 \\
\hline $\begin{array}{l}\text { Total Sol ids } \\
\left.\text { (TS } 103^{\circ} \mathrm{C}\right)\end{array}$ & 207 & 2,090 & 4,135 & 13,400 & 11,850 \\
\hline $\begin{array}{l}\text { Total Volatile } \\
\text { Solids (TVS } 550^{\circ} \mathrm{C} \text { ) }\end{array}$ & 191 & 862 & 2,155 & $16,790 *$ & $12,800 *$ \\
\hline $\begin{array}{l}\text { Total Fixed } \\
\text { Sol ids (TFS } 550^{\circ} \mathrm{C} \text { ) }\end{array}$ & 16 & 17 & 43 & $1,280 *$ & $1,000 *$ \\
\hline $\begin{array}{l}\text { Total Suspended } \\
\text { Solids (TSS } 103^{\circ} \mathrm{C} \text { ) }\end{array}$ & 17 & 69 & 316 & 460 & 1,040 \\
\hline $\begin{array}{l}\text { Conductivity } \\
(\mu \mathrm{mhos} / \mathrm{cm})\end{array}$ & 29 & 520 & 1,300 & $7,800 *$ & $4,570^{*}$ \\
\hline $\begin{array}{l}\text { Phenophthalein } \\
\text { Acidity (as } \mathrm{CaCO}_{3} \text { ) }\end{array}$ & 154 & 172 & 431 & $8,280 *$ & $4,390 *$ \\
\hline $\mathrm{pH}$ & 3.7 & 5.5 & 5.5 & $4.0-5.0$ & $3.5-5.5$ \\
\hline $\mathrm{NH}_{3}-\mathrm{N}$ & 0.32 & 93 & 233 & $1,180 *$ & $600 *$ \\
\hline $\begin{array}{l}\text { Total Kjeldah1 } \\
\text { Nitrogen }\end{array}$ & 1.9 & 218 & 546 & $2,810^{*}$ & $1,970 *$ \\
\hline $\mathrm{Fe}$ & 10.3 & 8.16 & 20.4 & $600 *$ & $490 *$ \\
\hline K & 0.42 & 3.32 & 8.3 & $52^{\star}$ & $50^{*}$ \\
\hline $\mathrm{Ca}$ & 2.0 & 4.24 & 10.6 & $70 *$ & $65 *$ \\
\hline $\mathrm{Mg}$ & 0.04 & 0.28 & 0.7 & $4^{*}$ & $3 *$ \\
\hline $\mathrm{Na}$ & 0.10 & 0.36 & 0.9 & $10 *$ & $9 *$ \\
\hline
\end{tabular}

*Composition prior to biological pretreatment. 
RESULTS

Results for the 33 RO experiments treating BGW are presented in the following tables, figures, and text. A discussion of these results follows in the discussion section.

SALT REJECTION

In order to ensure that a "tight" membrane has been installed in the pressure vessel and that the membrane has kept its integrity over the length of an experiment, salt solutions were passed through the membrane before and after each experimental run. Results of these analysis are presented in Table 3. The average salt rejection, calculated by using Equation 3 before each experimental run, was $99.8 \%$. Results assumed equilibrium concentrations were reached after $1 \mathrm{hr}$ operation. Salt rejection after each run averaged $98.5 \%$, however rejection results from BGW 6 experiments (95.8\%) were much lower than for other feeds causing this lower average value. Elimination of the BGW 6 value results in the average salt rejection value increasing to $98.9 \%$.

\section{PERMEATE FLUXES}

Permeate flux values were monitored in order to obtain data for design considerations, possibly including plant size and capacity. Permeate fluxes for the seven sets of feed are presented in Table 4. Fluxes appear to be highly variable, although exclusion of 50:1 and BGW 6 feed values result in an average flux range of 9-10 gal per sq ft per day (GFD). Variability in data, as shown by standard deviation values, was large for 50:1, BGW 6, and WAO.

CHEMICAL OXYGEN DEMAND REMOVAL

Feasibility of RO as a cleanup methodology must eventually be evaluated in terms of solute removal. In this case the removal of COD, using Equation 4, was used to test for solute removal. The percentage of COD removed by feed is presented in Table 5 . With the exception of the 50:1 feed, those feeds undergoing biological pretreatment had much better COD removal percentages (average of 98\%) than those without biological pretreatment. BGW 6 and WAO feeds averaged 90\% COD removal, however, they eventually fouled the membrane surface, a problem not observed when using the other feeds. With the exception of the 50:1 feed, variability in data points (see standard deviation) was small. 
TABLE 3. Average Salt Rejection for Seven Test Feeds

$\begin{array}{ccc}\text { Wastewater } & \begin{array}{c}\text { Salt Rejection Before } \\ \text { Experimental Run, } \%\end{array} & \begin{array}{c}\text { Salt Rejection After } \\ \text { Experimental Run, } \%\end{array} \\ 50: 1 & 99.8 & 99.5 \\ 25: 1 & 99.4 & 98.6 \\ 10: 1 & 99.7 & 99.5 \\ \text { AN 4 } & 99.9 & 98.9 \\ \text { AER 1-3 } & 99.9 & 99.3 \\ \text { BGW 6 } & 99.8 & 95.8 \\ \text { WAO } & 99.8 & 97.8 \\ \text { Average } & 99.8 & 98.5\end{array}$

TABLE 4. Average Permeate Fluxes for Seven BGW Feeds

No. of Permeate Fluxes (GFD)

Feed Experiments Average Standard Deviations

$\begin{array}{lrrr}50: 1 & 5 & 5.83 & 1.19 \\ 25: 1 & 4 & 8.85 & 1.27 \\ 10: 1 & 10 & 10.64 & 1.24 \\ \text { AN } 4 & 5 & 9.10 & 0.90 \\ \text { AER } 1-3 & 3 & 10.54 & 0.76 \\ \text { BGW } 6 & 2 & 3.38 & 2.90 \\ \text { WAO } & 3 & 9.45 & 3.30\end{array}$


TABLE 5. Average Chemical Oxygen Demand Removal for Seven BGW Feeds

\begin{tabular}{ccccc} 
Feed & & $\begin{array}{c}\text { No. of } \\
\text { Experiments }\end{array}$ & & \multicolumn{2}{c}{ COD Removal, $\%$} \\
$50: 1$ & 4 & & 69 & $\begin{array}{c}\text { Standard } \\
\text { Deviation }\end{array}$ \\
$25: 1$ & 5 & 94 & 8.1 \\
$10: 1$ & 9 & 98 & 0.4 \\
AN 4 & 5 & & $\sim 100$ & 0.1 \\
AER 1-3 & 3 & & 2100 & 0.2 \\
BGW 6 & 2 & 89 & 1.3 \\
WA0 & 3 & 91 & 0.2
\end{tabular}

COD REMOVAL VS TIME

Normally experiments were run 8-12 hrs, too short a time frame for measuring separation vs time. In order to check this trend, three experiments were run for approximately $26 \mathrm{hrs}$. Feeds for these three experiments were AN-4 and AER 1-3. Results of permeate COD values vs time are plotted in Figure 5 . The data for each experimental run have been fitted to a straight line. In general, data indicate increasing permeate COD values with time, an apparently negative result. However, one should recall that the solute concentration is constantly increased in the feed as permeate as removed. When a curve of percent $C O D$ removed vs time is plotted from results in Figure 5 , one can see that COD removal remained essentially constant with time (Figure 6 ).

\section{COLOR REMOVAL}

Color removal, normally considered in tertiary treatment processes, was measured for all experiments except those using 50:1 feed. Feed experiments of 50:1 were completed prior to initiation of color analysis. Results of color removal, calculated using Equation 3, are presented in Table 6 . Nearly $100 \%$ color removal was observed for all experiments. Standard deviations for the seven data sets are relatively small indicating consistent results for color removal. 


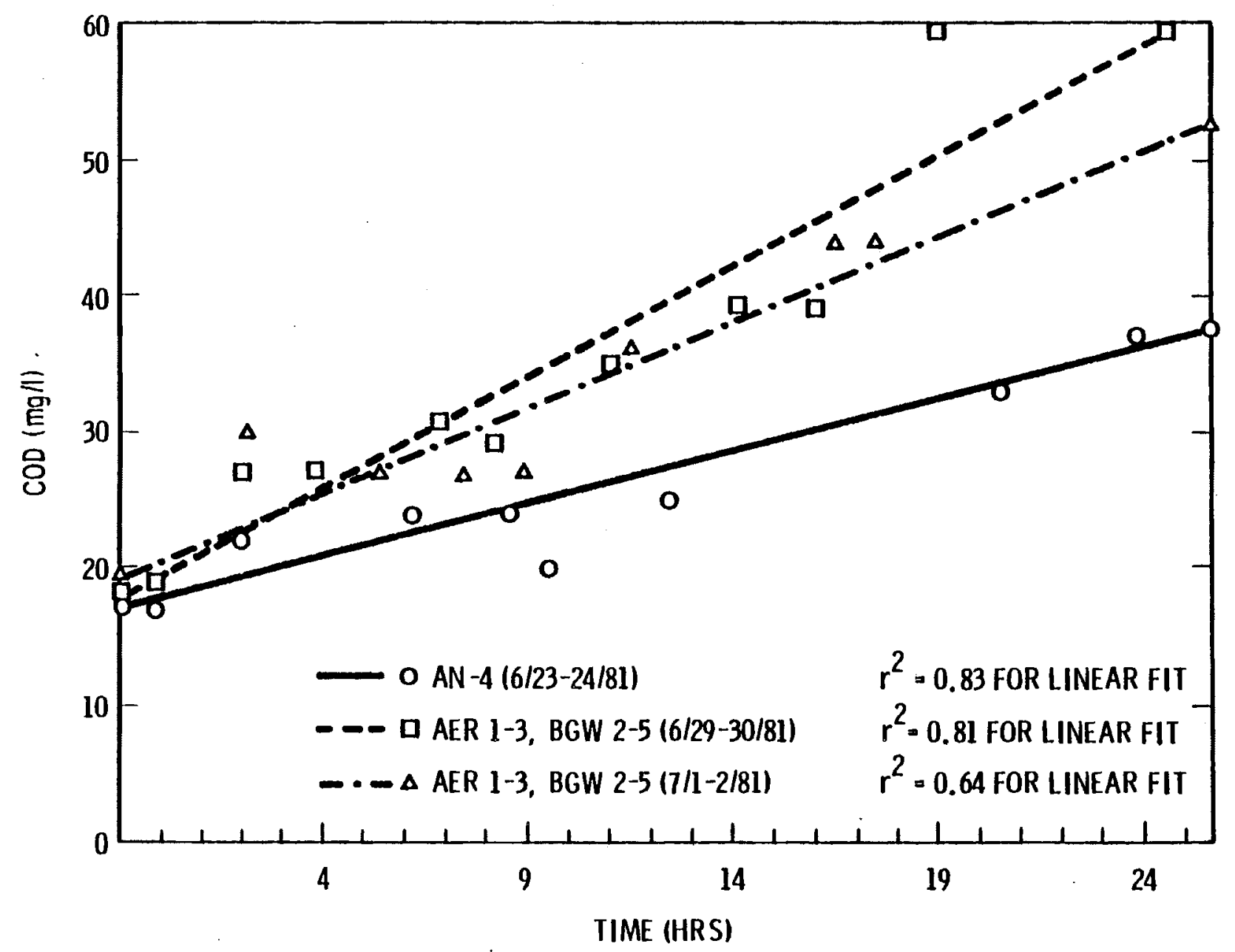

FIGURE 5. Chemical 0xygen Demand Removal Vs Time 


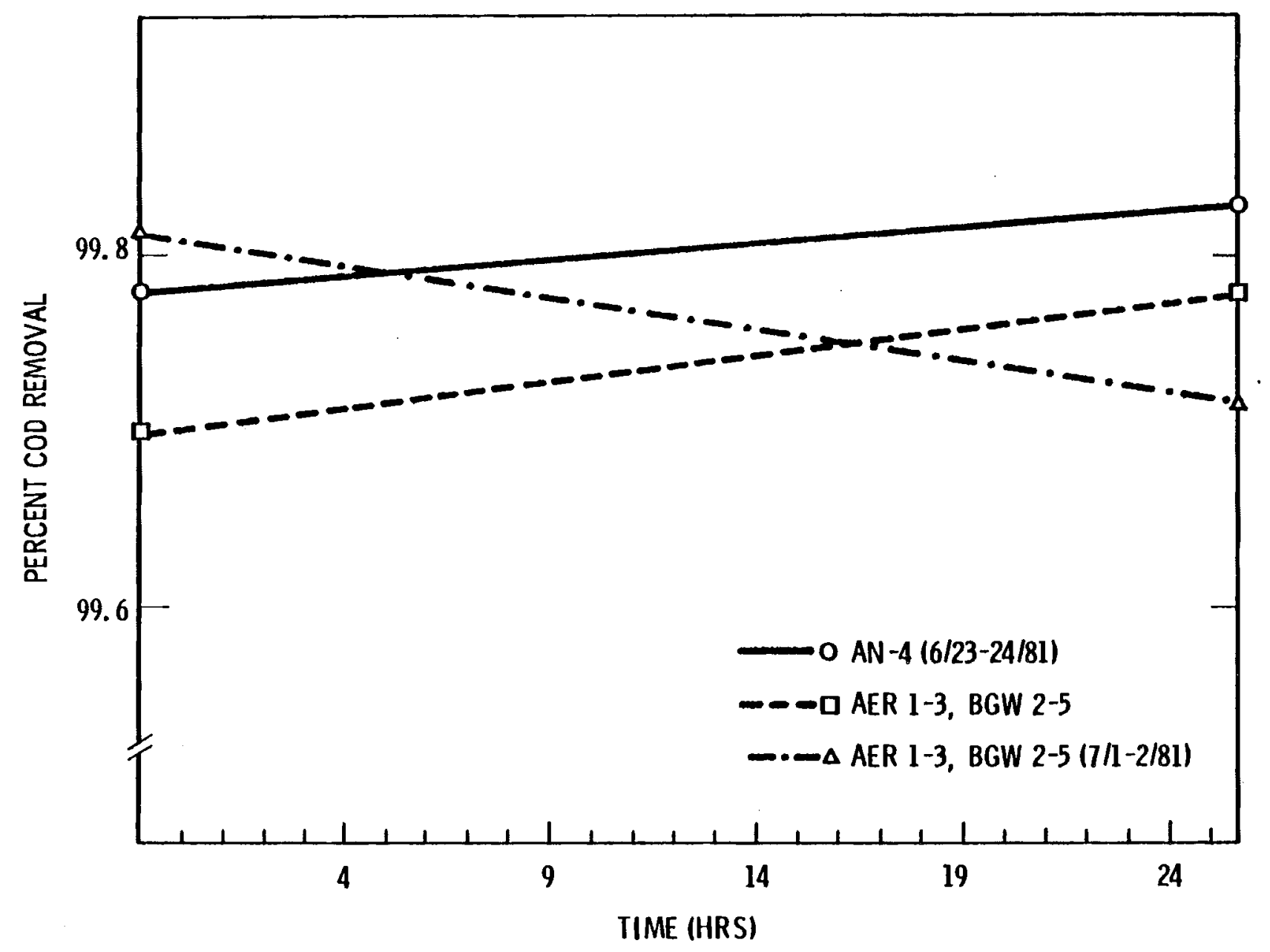

FIGURE 6. Permeate Chemical 0xygen Demand VS Time 
TABLE 6. Average Color Removal for Seven BGW Feeds

\begin{tabular}{ccccc} 
Feed & & $\begin{array}{c}\text { No. of } \\
\text { Experiments }\end{array}$ & & \multicolumn{2}{c}{ Color Removal, $\%$} \\
\cline { 1 - 1 } $50: 1$ & & 6 & & $\begin{array}{c}\text { Average } \\
\text { Standard } \\
\text { Deviation }\end{array}$ \\
$25: 1$ & 5 & 99 & - \\
$10: 1$ & 10 & 2100 & 0.2 \\
AN $\cdot 4$ & 5 & 2100 & 0.0 \\
AER 1-3 & 3 & 2100 & 0.0 \\
BGW 6 & 2 & 99 & 0.1 \\
WA0 & 3 & 99 & 1.1
\end{tabular}




\section{DISCUSSION OF RESULTS}

The following discussion sections present information derived from experimental results. Information is presented in the same order as were data in the experimental results section presented earlier.

\section{SALT REJECTION}

Salt rejection values of $99.4 \%$ are reported by the manufacturer of our test membrane. This value compares with an initial salt rejection value of $99.8 \%$ observed during all our experimental runs which indicate all membranes tested were up to quality control standards set by the manufacturer. Only two experiments required initial membrane replacement because of poor salt rejection (initial salt rejection values less than $98 \%$ ).

With the exception of experimental runs using BGW 6 and WAO, final salt rejection values remained high ( $99.2 \%$ ) indicating negligible membrane deterioration. Final salt rejection values for BGW 6 and WAO do indicate that membrane tightness (capacity for solute rejection) has decreased, especially considering these runs were normally discontinued because of membrane fouling (see permeate flux results). Degradation of the membrane surface appears to be enhanced when using feeds not being pretreated by biological processes. Since biological processes are very effective in reducing carboxylic (acetic and propionic) acids, which are common constituents of BGW (Kao, 1980) and which were not removed in BGW 6 and WAO feeds, the degradation of membrane surfaces for these feeds was probably due to the presence of acetic and propionic acids. This conclusion is also substantiated by the fact that acetic acid is not well separated by R0 membranes (Matsuura and Sourirajan, 1973). The presence of acetic and propionic acids in the feeds also appears to impact product quality and quantity, as discussed in the following sections.

\section{PERMEATE FLUXES}

With the exception of 50:1 and BGW 6 feeds, average permeate fluxes of 10 GFD were observed. Manufacturer's data for desalination reports values of 17 GFD. The difference in values is most likely due to differences in feed solutes. Because flux is a function of the driving force (pressure) and because the pressure term is the applied minus the osmotic 
pressure $\left(\Delta P-\Delta \pi^{\circ}\right)$, differences in fluxes for various solutes will change because each solute exerts its own osmotic pressure. This increase or decrease in the osmotic pressure of the solute will, under conditions of constant applied pressure, change the rate at which the solvent will pass through the membrane. Table 7 presents values of the water permeability constant $\left(W_{p}\right)$ as defined in Equation 1, along with values of solute permeability $\left(K_{p}\right)$ as defined in Equation 2. These parameters are typically used to evaluate a membrane's performance.

TABLE 7. Solvent and Solute Transport Parameters

\begin{tabular}{|c|c|c|}
\hline Feed & $W p\left(\frac{\mathrm{g}}{\mathrm{cm}^{2} \cdot \mathrm{sec} \cdot \mathrm{atm}}\right)$ & $\mathrm{Kp}\left(\frac{\mathrm{cm}}{\mathrm{sec}}\right)$ \\
\hline $50: 1$ & $4.22 \times 10^{-6}$ & $1.2 \times 10^{-6}$ \\
\hline $25: 1$ & $8.71 \times 10^{-6}$ & $5.6 \times 10^{-8}$ \\
\hline $10: 1$ & $10.93 \times 10^{-6}$ & $4.0 \times 10^{-9}$ \\
\hline AN 4 & $9.54 \times 10^{-6}$ & $3.4 \times 10^{-10}$ \\
\hline AER $1-3$ & $11.05 \times 10^{-6}$ & $6.4 \times 10^{-11}$ \\
\hline BGW 6 & $3.15 \times 10^{-6}$ & $1.0 \times 10^{-9}$ \\
\hline WAO & $8.81 \times 10^{-6}$ & $1.0 \times 10^{-8}$ \\
\hline
\end{tabular}

Use of Equation 1 for $W_{p}$ is complicated because computation of osmotic pressure for multiple solute systems cannot be done. The osmotic pressure for simple binary systems can be computed based on solution chemistry relationships. These computations (Appendix B) indicate osmotic pressures for acetic and propionic acids, 7830 and 5370 psi, respectively, are much higher than the experimental operating pressures of $700 \mathrm{psi}$. Therefore, these two solutes will leak through the membrane by simple osmosis. The other constituents are present in low enough concentrations that the total osmotic pressure was considered negligible in comparison with operating pressure when computing $W_{p}$. Values for $W_{p}$ are typical of those for RO membranes (Petty and Maxham, 1980).

Computation of $K_{p}$ was completed using COD concentration values rather than mass concentration values. These two concentration terms are essentially constant in this case since the predominate species, acetic acid, has a theoretical COD of 1.07 grams per gram of pollutant. 
Solute permeability is essentially a diffusion coefficient which indicates the rate of solute (BGW organics) movement through the membrane. Comparison of present $K_{p}$ values with those computed in other studies indicates this membrane is less solute permeable than membranes used in desalination studies. Values of $k_{p}$ calculated in the current study are lower than others reported, but still highly variable. As the wastewater strength, using biologically pretreated wastewaters, increased, $K_{p}$ values decreased. This is probably due to fixed levels of organics which the RO unit will not remove which becomes proportionaliy smaller as the wastewater strength increases (i.e., $\Delta C$ gets larger).

Permeate flux values for 50:1 feeds were abnormal1y low in comparison with other biologically pretreated feeds. This may be due to the presence of milk solids in the feed added during biological pretreatment. These milk solids may have plugged the membrane surface, lowering permeate flux values.

Extremely low permeate flux values were observed for BGW 6 feed runs. The experiments using this feed were all prematurely stopped because of membrane fouling (lack of permeate flux). It was speculated that the carboxylic acids in the feed degraded the membrane resulting in degradation products plugging the membrane. Inspection of the membrane after the experimental runs confirmed this speculation.

An additional problem stemmed from the presence of ammonia in the feed which solubilized copper from an in-line copper-tubed heat exchanger. The two experiments run prior to replacing the copper-tubed heat exchanger with a glass-tubed heat exchanger contained precipitated copper ion which also caused visible plugging of the membrane surface. Average flux data for BGW 6 experiments includes results from the two experiments using copper-tubed heat exchangers. This may explain low flux values for BGW 6 tests.

A large variation (standard deviation values of 3.30 GFD) in WAO fed experiments reflects uncertainty in using RO for purification of BGW having undergone WAO pretreatment. Several of the experiments with this feed were discontinued due to fouled membranes. Since WAO processes do not normally remove acetic acid (in some cases WAO increases levels of acetic acid), membrane plugging may be due to the degradation of the membrane surface by acetic acid. A decrease in water quality (see COD removal results) supports this conclusion. 
CHEMICAL OXYGEN DEMAND

Several conclusions can be drawn from COD removal results. First, the difference between a successful and an unsuccessful RO treatment process (in terms of COD remova1) appears to depend on whether or not acetic acid is removed during a pretreatment process. The experiments using wastewaters pretreated by biological processes had almost complete COD removal. Of this group of feeds, only the 50:1 feed had low removal percentages (69\%), which was probably due to the presence of milk solids in the feed. Experiments using BGW 6 and WAO feeds had relatively high COD removals ( $89-91 \%$ ), but this is somewhat misleading. Experiments using these two feeds were normally discontinued after a few hrs of operation due to fouled membranes, a fact which may preclude the use of RO for treatment of these feeds. Lower COD removal percentages for those feeds containing acetic acid verify results of Chian and Fang - (1975) which indicated approximately $90 \%$ of totally dissociated acetic acid could be removed by the NS-100 membrane. Since nearly $70 \%$ of the COD in BGW was from acetic acid (Kao, 1980), the results here are in line with those of previous studies.

COLOR REMOVAL

Color in wastewaters is normally associated with large multiringed aromatic compounds. Inherently, RO is very effective in color removal (Weber, 1972) because RO typically removes compounds with molecular weights greater than 100, a value lower than that for most color producing organics. Color removals for all experimental runs were $99-100 \%$ which agree quite closely with $100 \%$ values reported in the literature (Weber, 1972). Visibly, all permeate samples were colorless in contrast to the brown, opaque feed samples. 


\section{REFERENCES}

APHA. 1980. Standard Methods for the Examination of Water and Wastewater. APHA, Washington, DC.

Baum, B., S. A. Margosiak and W. H. Holly, Jr. 1972. "Reverse Osmosis Membranes with Improved Compaction Resistance." Industrial Engineering Chemical Product Research and Development, Vol. 11, No. 2, pp. 195-199.

Butler, J. N. 1964. "Nonideality Corrections, Chapter 12." Ionic Equilibria: A Mathematical Approach. Addison-Wesley Publishing Company, Reading, MA.

Environmental Protection Agency. 1976. Manual of Methods for the Chemical Analysis of Water and Wastes. Cincinnati, $\mathrm{OH}$.

Fang, H. H. P. and E. S. K. Chian. 1975. "Removal of Alcohols, Amines, and Aliphatic Acids in Aqueous Solution by NS-100 Membrane." Journal of Applied Polymer Science, Vol. 19, p. 1347.

Fang, H. H. P. and E. S. K. Chian. 1976. "Reverse Osmosis Separation of Polar Organic Compounds in Aqueous Solution." Environmental Science and Technology, Vol. 10, №. 4, pp. 364-369.

Kao, C. H. 1980. Extraction of Waste Water From Biomass Gasification. Master's Thesis, Texas Tech University.

Lacy, E. R. 1972. "Membrane Separation Processes." Chemical Engineering, pp. 56-72.

Matsuura, T. and S. Sourirajan. 1971. "Reverse Osmosis Separation of Some Organic Solutes in Aqueous Solution Using Porous Cellulose Acetate Membranes." Industrial Engineering and Chemical Process Design and Development, Vol. 10, No. 1, pp. 102-108.

Matsuura, T. and S. Sourirajan. 1973. "Reverse Osmosis Separation of Organic Acids in Aqueous Solutions Using Porous Cellulose Acetate Membranes." Journal of Applied Polymer Science, Vol. 17, p. 3661.

Matsuura, T., J. M. Dickson and S. Sourirajan. 1976a. "Free Energy Parameters for Reverse Osmosis Separations of Undissociated Polar Organic Solutes in Dilute Aqueous Solutions." Industrial Engineering and Chemical Process Design and Development, Vol. 15, No. 1, pp. 149-161.

Matsuura, T., J. M. Dickson and S. Sourirajan. 1976b. "Predictability of Reverse Osmos is Separations of Partially -Dissociated Organic Acids in Dilute Aqueous Solutions." Industrial Engineering and Chemical Process Design and Development, Vol. 15, No. 2, pp. 350-357.

Matsuura, T., A. G. Baxter and S. Sourirajan. 1977. "Predictability of Reverse Osmosis Separations of Higher Alcohols in Dilute Aqueous Solutions Using Porous Cellulose Acetate Membranes." Industrial Engineering and Chemical Process Design and Development, Vol. 16, No. 1, pp. 82-89. 
Matsurra, T. and S. Sourirajan. 1978. "Characterization of Membrane Material, Specification of Membranes, and Predictability of Membrane Performance in Reverse Osmosis." Industrial Engineering and Chemical Process Design and Development, Vol. 17, No. 4, pp. 419-428.

Maxham, J. V. and N. E. Be11. 1980. Treatment of Biomass Gasification Wastewater. Presented at the 11th Biomass Thermochemical Conversion Contractors Meeting, September 23-24, Richland, WA. PNL-SA-8921.

Maxham, J. V. 1981. Treatment of Biomass Gasification Wastewater. Presented at the 12th Biomass Thermochemical Conversion Contractors Meeting, March 18-19, Washington, DC.

Merten, U. 1966. Desalination by Reverse Osmosis. The MIT Press, Cambridge, MA.

Perry, R. H. and C. H. Chiton. 1973. Miscellaneous Separation Processes, Chapter 17." Chemical Engineers' Handbook, 5th Edition. McGraw-Hi11 Book Company, New York, NY.

Petty, S. E. and J. V. Maxham. 1980. Ethanol-Water Separation Using a Reverse Osmosis Process. PNL-3579. Battelle, Pacific Northwest Laboratory, Richland, WA.

Reed, S. A. and J. V. Wilson. 1977. Desalting Sea Water and Brackish Waters: A Cost Update. ORNL/7M-5926, Oak Ridge National Laboratory, Oak Ridge, TN.

Riley, R. L., R. L. Fox, C. R. Lyons, C. E. Milstead, M. W. Seroy and M. Tagami. 1976. Spiral-Would Poly/Ether/Amide Thin-Film Composite Membrane Systems. Presented at the Membrane Separation Technology Conference, August 2-6, Clemson University, Clemson, SC.

Riley, R. L., C. E. Milstead, A. L. Lloyd, M. W. Seroy and M. Tagami. 1977. Spiral-Wound Thin-Film Composite Membrane Sys tems for Brackish and Seawater Desalination by Reverse 0smosis. Presented at the International Congress on Desalination and Water Re-Use, November 27December 3, Tokyo, Japan.

Riley, R. L., P. A. Case, A. L. Lloyd, C. E. Milstead and M. Tagami. 1980. Recent Developments in Thin-Film Composite Reverse Osmosis Membrane Systems. Presented at the Joint Symposium in Water Filtration and Purification, June 9-12, Philadelphia, PA.

Stumm, W. and J. J. Morgan. 1970. "Acids and Basis, Chapter 3." Aquatic Chemistry: An Introduction Emphasizing Equilibria in Natural Waters. Wiley-Interscience, New York, NY.

Weber, W. J., Jr. 1972. "Membrane Processes, Chapter 7." Physicochemical Processes for Water Qual ity Control. John Wiley and Sons, Inc, New York, NY. 
APPENDIX A

REVERSE OSMOSIS TEST PROCEDURE 


\section{REVERSE OSMOSIS TEST PROCEDURE}

1) Prepare in advance two $500 \mathrm{ml}$ solutions of $2 \mathrm{~g} / 1$ sodium chloride $(\mathrm{NaCl})$ and filter $500 \mathrm{mls}$ of the wastewater sample to be used for the actual test run.

2) Load RO membrane into the holding cell and tighten all four corners as evenly and securely as possible.

3) Place the holding cell on the RO unit and attach the appropriate tubing lines. NOTE: Make sure to use teflon tape on the threaded portion of the fittings.

4) Standardize the conductivity meter according to specifications in the instruction booklet.

5) Setup automatic sampler -- set timer at 15 min intervals, fill sampling rack with clean and dry test tubes, and position permeate line holding arm correctly over test tubes.

6) Place one of the $500 \mathrm{ml} \mathrm{NaCl}$ solutions in a graduated cylinder. Place the graduated cylinder in the center holding tank of the RO unit and then place the cooling soil into the cylinder.

7) Flush the RO system with distilled water until the protective surface of the membrane has been washed away (the reject flow will turn from milky white to clear). NOTE: At this time 200-400 psi is sufficient to clean the membrane surface. Check for pressure leaks. If no leaks are found, proceed.

8) Once the reject flow becomes colorless, increase the pressure to $600 \mathrm{psi}$ using the pressure valve on the pump and the back pressure valve.

9) At this time, prepare to switch from the distilled water rinse to the $\mathrm{NaCl}$ solution. This is done by simultaneously placing the feed and reject lines in the graduated cylinder in such a way that the feed line goes to the bottom and the reject flow cascades down the cooling.coil. NOTE: This procedure should be done as quickly as possible to eliminate excess air in the lines (two people can do the task much easier and faster than one). Throughout the changeover, a psi of 600 should be maintained. Pressure and temperature measurements should be made every 15 min throughout the $\mathrm{NaCl}$ run and adjustments made to keep the pressure constant and the reject flow temperature below $40^{\circ} \mathrm{C}$.

10) The permeate line should not be placed in a beaker to gather any flow. After approximately 35-40 min, individual samples should be taken and measured for conductivity. Once the conductivity drops below $200 \mathrm{micromhos} / \mathrm{cm}$, turn off the system and release the pressure. NOTE: If the conductivity does not drop significantly in 45-50 min, this would indicate a small hole or crack in the RO membrane. If this happens, the test run should be terminated and a new membrane should be placed into the pressure vessel. 
11) Assuming that the membrane has achieved $95 \%$ removal (a conductivity of 200 micromhos/cm or less) rinse the system again at low pressure and minimal back pressure for approximately 5 min with distilled water.

12) Dispose of the used $\mathrm{NaCl}$ solution and rinse off the cooling coil. Replace the $\mathrm{NaCl}$ solution with the $500 \mathrm{ml}$ wastewater sample for the actual test run. Replace cooling coil and collect a $50 \mathrm{ml}$ sample of the wastewater to be saved for comparison with the permeate and feed samples to be collected.

13) Increase the pressure to $600 \mathrm{psi}$ and position the permeate line on the holding arm of the automatic sampler.

14) At this time make the switch from the distilled water rinse to the wastewater sample using the same method as Step No. 9. At this time it is also important to turn on the automatic sampler which will begin taking samples every $15 \mathrm{~min}$ for the first $\mathrm{hr}$, and every half-hr thereafter. It is important to keep the pressure as constant as possible and the temperature of the reject flow below $40^{\circ} \mathrm{C}$ throughout the duration of the wastewater run (approximately $5 \mathrm{hr}$ ). Take initial feed sample.

15) Once an hr a feed sample should be taken and saved. All samples should be covered as they are collected to prevent any evaporation that might otherwise occur.

16) Run the RO unit until the feed sample has been depleted. Turn off the unit and release the pressure.

17) Measure volume of feed left in the cylinder and save a $50 \mathrm{mi}$ sample. At this time place all the samples collected before, during, and after the test run in test tube racks and store under refrigeration until they can be analyzed the following day. NOTE: It is extremely important to make sure the samples remain in order.

18) Setup the second $\mathrm{NaCl}$ solution following the procedure in Step No. 6.

19) Rinse the system at low pressure and minimal back pressure for approximately 5 min with distilled water.

20) Increase the pressure to 600 psi using the pressure valve on the pump and the back pressure valve.

21) Follow Steps No. 9 and 10: NOTE: Automatic sampler should be used on final $\mathrm{NaCl}$ run as opposed to manual sampling.

22) Remove the membrane from the holding cell and examine it visually. Dry off the cell and wipe down the Ro unit, automatic sampler, and surrounding area. 
1) Remove samples from refrigeration and allow them to warm up to room temperature.

2) Measure each of the sample's volume and, if necessary, combine them in order until their cumulative volume reaches $15 \mathrm{mls}$.

3) Because of limited sample sizes from the RO test, it becomes necessary to obtain good sample analysis the first try. Therefore, it is necessary to determine what ranges the sample's COD value is within. The Hach Micro COD method has been selected for this purpose.

4) Once the approximate COD range has been established, the remaining portion of the samples will be tested for COD values using Standard Methods, 14th Edition, Oxygen Demand (chemical) test.

5) Add color analysis procedure.

6) Add suspended solids procedure. 
.

. 
APPENDIX B

COMPUTATION OF ACTIVITY COEFFICIENTS 


\section{DETERMINATION OF OSMOTIC PRESSURE}

FOR WASTEWATER CONSTITUENTS

Osmotic pressure $\left(\pi^{\circ}\right)$ can be computed using the following equation:

$$
\pi^{0}=-\left(\frac{R T}{\overline{V_{W}}}\right) \ln a_{w}=-\left(\frac{R T}{\bar{V}_{W}}\right) \ln \left(\gamma_{w} X_{w}\right)
$$

where

$$
\begin{aligned}
& \pi^{\circ}=\text { osmotic pressure (psi) } \\
& R=\text { gas constant }=10.73 \frac{(p s i)\left(\mathrm{ft}^{3}\right)}{\left(\text { (b-mole) }{ }^{\circ} \mathrm{R}\right)} \\
& T=\text { temperature in }{ }^{\circ} \mathrm{R}=525^{\circ} \mathrm{R} \\
& \bar{V}_{W}=\text { partial molal volume of water in solution }=\frac{18.02 \frac{7 \mathrm{~b}}{\mathrm{lb}}-\mathrm{mole}}{62.4 \frac{\mathrm{Tb}}{\mathrm{ft}^{3}}}= \\
& 0.2887 \frac{\mathrm{ft}^{3}}{\mathrm{~Tb}-\mathrm{moTe}} \\
& \gamma_{w}=\text { activity coefficient for water in solution } \\
& a_{w}=\text { activity of water in solution } \\
& x_{W}=\text { mole fraction of water } \\
& \therefore \pi^{\circ}=(19,512) \ln \left(\frac{1}{\gamma_{x} W_{x}}\right)
\end{aligned}
$$

From Stumm and Morgan (1970) and Butler (1964), the Davies equation for computing activity coefficients can be used as long as the ionic strength of the solvent and solute is below $0.5 \mathrm{M}$.

$$
\ln \gamma=-A Z^{2}\left(\frac{\sqrt{I}}{1+\sqrt{I}}-0.2 I\right)
$$

where

$$
\begin{aligned}
I= & 1 / 2 \sum C_{i} Z_{i}^{2} \text { (ionic strength) } \\
A= & 0.509 \text { for water at } 25^{\circ} \mathrm{C} \\
Z= & \text { ionic charge } \\
C_{i}= & \text { concentration of species "i" } \\
& \therefore I=1 / 2\left[C_{H+}(1)^{2}+C_{A C}-(-1)^{2}\right]=C_{A C} \text { - since } C_{H+}=C_{A C}{ }^{-}
\end{aligned}
$$

Since the wastewater had a $\mathrm{pH}$ of 7-9, all the acids can be assumed to be totally dissociated (Butler, 1964; Fang and Chian, 1975). Assuming 
a typical BGW compositional analysis, presented by Kao (1980), ionic strength can be computed for each of the major constituents (Table B-1). This analysis shows the main pollutants consist of acetic and propionic acids. Davies' equation can then be solved using the ionic strengths which are computed from ionic concentrations. For acetic acid:

$$
C_{A C^{-}}=\left(\frac{26.150 \mathrm{~g}}{1}\right) 1\left(60.06 \frac{\mathrm{g}}{\mathrm{g}-\mathrm{mo} \mathrm{e}}\right)=0.4355 \mathrm{M}
$$

and for propionic acid:

$$
C_{P_{r}}=\left(\frac{6.161 g}{l}\right) 1\left(74.1 \frac{\mathrm{g}}{g-m 07 e}\right)=0.083 \mathrm{M}
$$

Plugging these values into the Davies equation results in the following activity coefficients for acetic and propionic acid:

$$
\begin{aligned}
& \gamma(\text { acetic acid })=0.69 \pm 8 \% \\
& \gamma(\text { propionic acid })=0.78 \pm 3 \%
\end{aligned}
$$

Osmotic pressure for each of these constituents, using an $x_{w}$ of 0.97 , are 7830 and 5370 psi for acetic and propionic acid, respectively.

TABLE B-1. Analysis of a Typical BGW

\begin{tabular}{lcc}
\multicolumn{1}{c}{ Compound } & $\frac{c}{\text { Concentration }}(\mathrm{g} / \mathrm{BGW})$ \\
Acetic Acid & & 26.150 \\
Propionic Acid & 6.161 \\
Methanol & 3.382 \\
Acetone & 0.660 \\
Formic Acid & 0.488 \\
Ethanol & 0.394
\end{tabular}




\section{DISTRIBUTION}

No. of

Copies

OFFSITE

A. A. Churm

DOE Patent Division

9800 South Cass Avenue

Argonne, IL 60439

Ray Costello

Biomass Energy Systems Division

U.S. Department of Energy

600 E Street, N. W.

Mail Stop 404

Washington, DC 20545

27 DOE Technical Information Center

J. V. Maxham

Institute of Paper Chemistry

Appleton, WI 54911

ONSITE

Richland Operations Office

H. E. Ransom

22 Pacific Northwest Laboratory

N. E. Bell

D. B. Cearlock

G. W. Dawson

C. J. English

A. F. Gasperino

S. E. Petty (10)

Publishing Coordination (2)

Technical Information (5) 


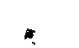

.

, 